\title{
Towards Effective Inventory Management Of Health Commodities At Service Delivery Points: A Case Of Health Personnel In Shamva District, Zimbabwe
}

\author{
Kunaka Taurai Rogers \\ Chinhoyi University of Technology \\ Chavunduka M. Desderio \\ Chinhoyi University of Technology
}

\begin{abstract}
Despite much effort at improving availability of health commodities, stock-outs and expiries are still commonplace at service delivery centres. The success of any inventory management programme relies on the people undertaking it and there seems to be a missing link in the supply chain that could be related to the people tasked with inventory management at service delivery points. The study thus sought to assess whether the personnel's knowledge, attitude, perceptions and practices are the missing link resulting in stock-outs and expires. The study employed a mixed method approach wherein quantitative and qualitative data collection methods were employed. The data collected sought to explore various aspects of the personnel including the training facility regarding inventory management, personal attitudes and, perceptions and practices towards certain inventory management aspects. Clearly it was found that personnel knowledge levels were very low, attitudes and perceptions veer in the negative whilst practices are not up to standard. This correlated to the availability of drugs and commodities at service delivery points.
\end{abstract}

Key words: health commodities, expiries, stock outs, Inventory management.

\section{INTRODUCTION}

Compared to the manufacturing, the health sector lags behind in the utilization of the benefits that could be derived from effective inventory management (Singh, 2006, Long, 2005). Most governments in low-income countries, notably in sub-Saharan Africa, choose a distribution model where the government procures drugs and distributes them to health clinics using the publicly run Central Medical Store (CMS) and a government-owned transport fleet (Yadao; 2015). Studies on stock-outs and expiries experienced in primary health care centres are indicative that inventory management is still an issue. Mahoro (2013) notes that in the Western Cape Province of South Africa stock-outs and expiries were mainly indicative of poor inventory management, lack of knowledge on inventory management and a neglect of stock monitoring which culminates in poor record-keeping practices. Agrawaj et al (2016) allude to a similar situation in Senegal and 
according to MHS (2012), there is a realization that personnel at the primary level lag behind in terms of the right skills, knowledge, and practice when undertaking inventory management.

In Zimbabwe, the Assisted Pull System (APS) is used for distribution of commodities in healthcare in the country. While the rollout of the has greatly improved efficiency and effectiveness in ordering and distribution of health commodities, problems of stock-outs and expiries still exist and seem to be growing. This is shown in systematic monitoring reports which also reveal that information collected is not consistent with what is on the ground.

Consequently, the low-income group who are supposed to be covered by public health facilities end up not receiving the commodities for their health requirements. This includes people living with HIV, patients on TB treatment, women on reproductive health products and children on nutritional supplements. Chingarande (2018) alludes to a situation where HIV/AIDS patients are at risk after the crucial drug expired in many health centres across the country. Over 750000 people were affected whilst thousands of dollars' worth of the drug had to be destroyed due to expiry (ibid). Similarly, Zimbabwe ran out of fixed-dose combinations for TB treatment (Kadirire, 2018). One aspect attributable to these stock-outs and expiries is poor inventory management.

This study aimed at investigating the causes, context and effects of personnel's knowledge, attitude, perception, and practices on inventory management at service delivery points in the Shamva District of Zimbabwe. The map below shows the primary health care centres in the district.

\section{Shamva Health Facilities}

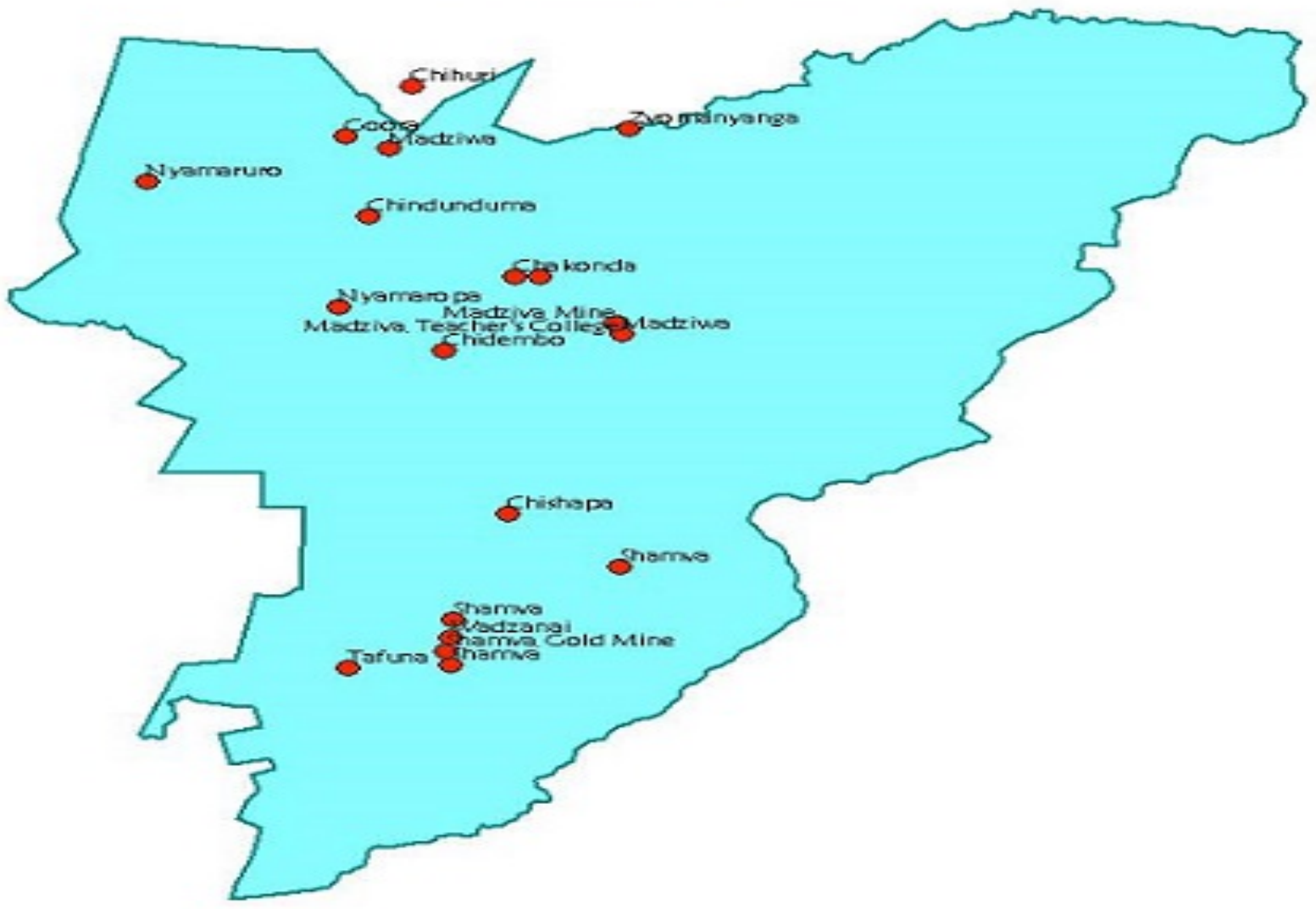

Fig I: Primary health care centres (Shamva) 
Rogers, K. T., \& Desderio, C. M. (2020) Towards Effective Inventory Management Of Health Commodities At Service Delivery Points: A Case Of Health Personnel In Shamva District, Zimbabwe. Archives of Business Research, 8(5). 248-262.

Shamva has been designated as the focus of this particular research study due to the incessant stock-outs and expiries of commodities experienced in the district's primary health centres despite the use of the APS. Shamva can be used as a pilot study on whether and how personnel knowledge, attitudes, perceptions and practices (KAPP) affect inventory management and ultimately stockouts and expires.

\section{LITERATURE REVIEW}

Various scholars have advanced theories in relation to supply chain and inventory management in the health sector. The resource-based view (RBV) is hereby used to try and provide a deeper understanding of the healthcare supply chain and the inventory management process.

The RBV by Burncy (1991) is a general elucidation of how and why companies accomplish success resultant of the existence and deployment of organization-specific resources. In the health sector; scholars have adopted the RBV to differentiate the performance of healthcare centres, taking into account availability and management of resources (Hinterplattner; 2016; Wales et al. 2000; Chen et al. 2013). Resources in the health sector encompass medicines and those other commodities which imperatively need to be available and stored in the right quantity and conditions. Despite having overarching goals to accomplish, the manner that an organization chooses to fulfil its mission is often limited by resource availability (Hinterplattener, 2016; Rangan, 2004).

Whilst it is irrefutable that resources determine the smooth operation of health centres, studies have been skewed towards resources like medicines, vaccines, and other commodities and their contribution to quality service provision in the health sector. A resource that has received little attention is to do with the KAPP in the health personnel and the effect their actions have on various processes of health delivery ranging from the supply chain to provision of commodities to the end user (Hinterplattner; 2016). How a healthcare organization coordinates the deployment of its internal and external resources hugely affects strategic decision making and fulfilment of strategic goals. The supply chain management at a hospital is exclusively more complex and requires greater knowledge than the traditional supply chain industry and this can only be achieved if the healthcare personnel is equipped with the right knowledge, attitudes, perceptions and practices (KAPP) informing practice. Hence as an extension to medicines and other commodities human resources in the form of health personnel (KAPP) cannot be divorced from the ultimate service delivery level at health centres.

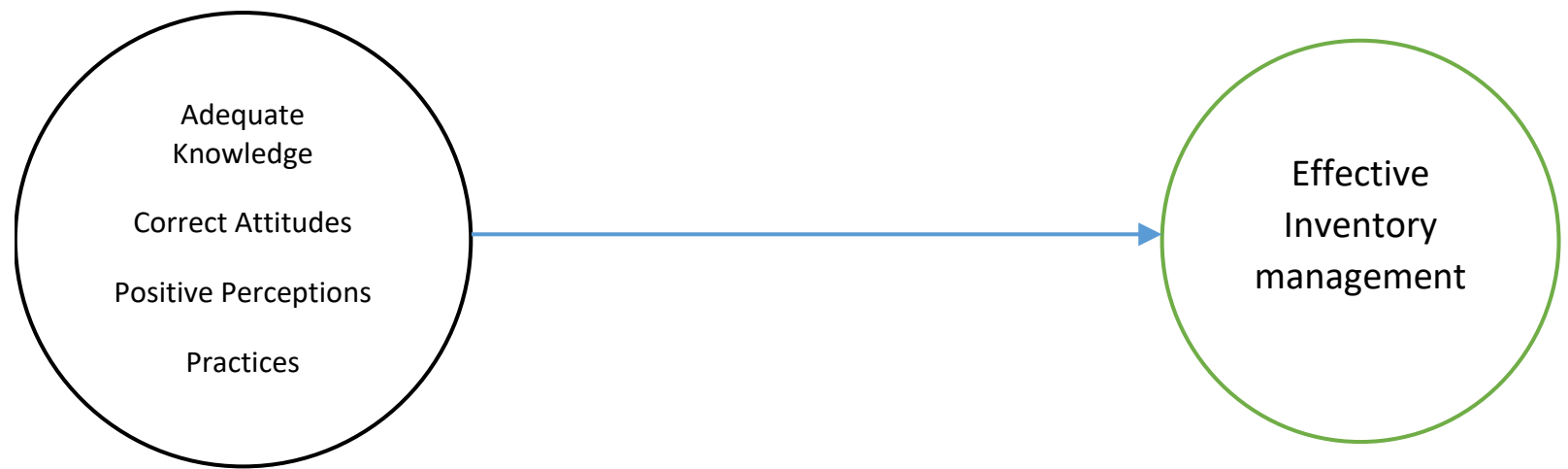

Fig 2: Conceptual framework 
The issues and concepts to be discussed and addressed by the study are illuminated diagrammatically by Fig II. This means that for effective and accurate inventory management to be undertaken the facilities in place should be supported by personnel with the right knowledge, correct attitudes and positive perceptions as this results in proper practices. Knowledge refers to what is known, attitude refers to the emotion one has over something, perception is how people view things (the importance attached to something) whilst practice refers to what is done and how it is done. According to Geer et al. (2006), Knowledge gaps lead to poor work attitude and negative perception translating into poor or incorrect action. Assessments that consider worker behaviour, attitudes and perceptions underlie explanations to personal contributions to the quality of healthcare delivery. An article by WHO (2008) recognizes the existence of barriers that may limit worker adherence to good inventory practices and the existence of a correlation between worker knowledge and ultimate action. As such for inventory management at service delivery points to be effective a deep analysis of personnel tasked with undertaking stock management is imperative and attention has to be given to how personnel KAPP impact on the effectiveness of inventory management.

\section{METHODOLOGY}

This research selected the pragmatism research philosophy which is basically a combination of the qualitative and quantitative research philosophies. Questionnaires were distributed to the nurses or dispensers at government service delivery points within Shamva district, to gather data for the assessment of their KAPP. The target population of this study was all health personals in Shamva district responsible with inventory a management of health commodities a total of 40 . Shamva District has got 20 health facility that deals with dispersing and management of health commodities.

This research adopted stratified random sampling, which involves a process of stratification of segregation of the population in homogenous groups (groups with the same characteristics). This is then followed by a random selection of subjects from each stratum. The researcher divided the population into 10 health facilities homogeneous subgroups. Then from each facility, we sample 2 (two) health personnel using simple random sampling technique was done through the lottery method.

\section{Results from the field}

\section{PRESENTATION OF RESULTS}

The most dominant designation in inventory management was Primary Care Nurse (PCN) with eleven respondents (55\%), Registered General Nurse (RGN) constitute the second most dominant designation with three (15\%) involved in inventory management activities, two Dispensary Assistants (DAs) which equates to $10 \%$ alluded to being involved in inventory management. Sister in Charge (SIC), State Certified Nurse (SCN) and General Hand (GH) are the least represented designations with one (5\%) personnel involved in inventory management activities. 


\section{Designation of respondent}

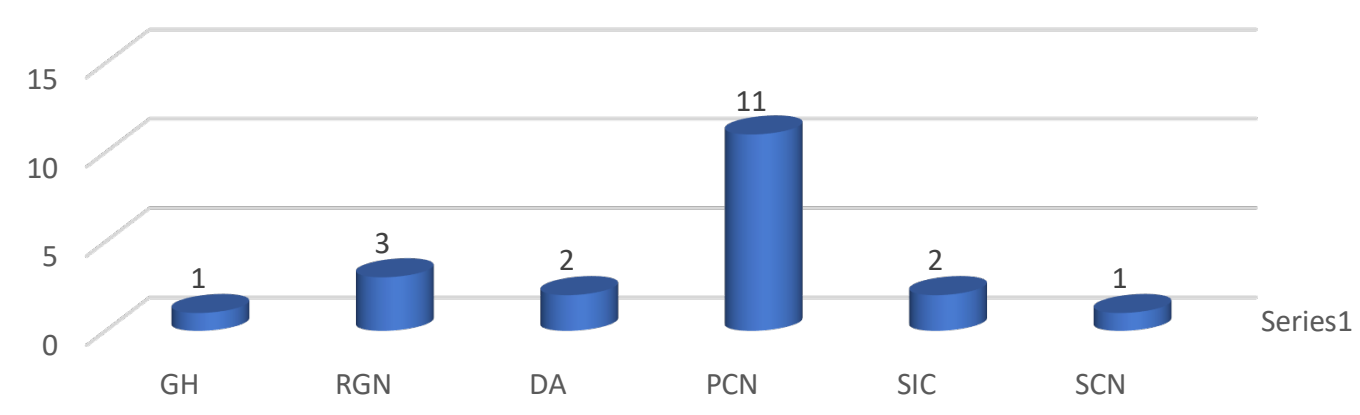

Fig 3: Graphical representation of designation of the respondent.

Source: Fieldwork (2018)

After initial training it is imperative for health personnel to be continually trained and reminded of the importance and process of inventory management. The study findings (table I) show minimal refresher training being undertaken by professionals in the field.

Table I: Distribution of refresh training in the past 2 years acquired by respondent

\begin{tabular}{|c|c|c|c|c|}
\hline Type of training & Yes & No & Yes (\%) & No (\%) \\
\hline trained ZAPS in the last 2 years & 7 & 13 & 35 & 65 \\
\hline trained ZADS in the last 2 years & 2 & 18 & 10 & 90 \\
\hline trained VMMC in the last 2 years & 1 & 19 & 5 & 95 \\
\hline trained MM in the last 2 years & 1 & 19 & 5 & 95 \\
\hline trained MCM in the last 2years & 8 & 12 & 40 & 60 \\
\hline
\end{tabular}

Although $60 \%$ of the respondents received initial training in ZAPS, only 35\% indicated they had received any additional or refresher training; compared to $45 \%$ of facility staff training in ZADS for refresher training the number fell drastically to $10 \%$ and a similar trend is observed in MM training where the $65 \%$ initially trained personnel are juxtaposed with the $10 \%$ who indicated they received any refresher training. The poor provision of refresher training to personnel can impact negatively on personnel KAPP as in addition to reinforcing the importance of inventory management (thus resulting in positive perceptions and attitudes), such training also introduces emerging themes, theories and concepts in inventory management to staff already employed at service delivery points. The low undertaking of refresher training by personnel in Shamva district is thus impinging on proper inventory management practices and ultimately affecting availability of commodities in a negative manner.

Fig IV below indicates the intervals at which facility staff indicated that they undertook inventory management. 


\section{Frequency of intventory management}

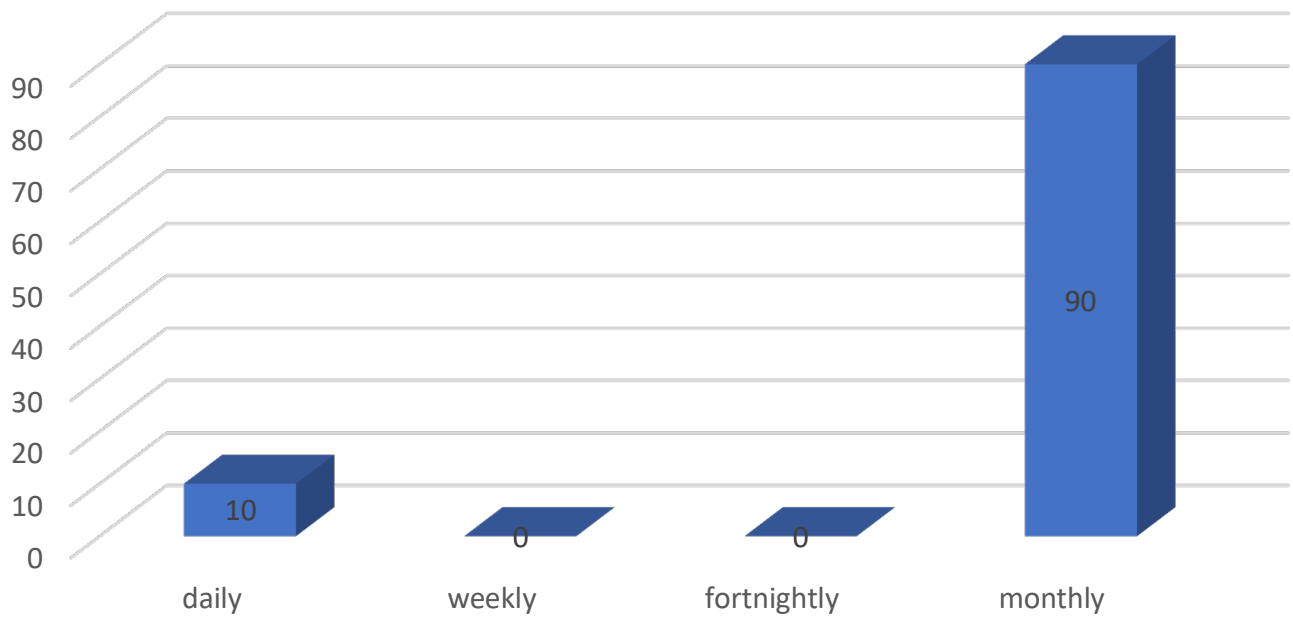

Source: Field work (2018)

Fig 4: Inventory management frequency

Under ZAPS and ZADS it is recommended that inventory management be done on a daily basis. However Fig. IV paints contrasting picture as of all the respondents involved in the study only $10 \%$ undertake inventory management on a daily basis as stipulated. The majority (90\%) undertake inventory management on a monthly basis. Such practices by personnel are indicative of negative perceptions and attitudes towards the importance of inventory management and this is detrimental to commodity availability and by extension quality service delivery.

The health commodities that are obtained from NatPharm and private sources are kept in a storeroom at each facility. The preference of health commodities was measured by asking the respondent which health commodity would he/she prioritize given a limited space (table II) and this was done in order to determine personnel preferences as these correlate to perception and attitude. Simply put personnel are more likely to priorities inventory of commodities they deem more important.

Table 2: Preference of drugs by personnel

\begin{tabular}{|c|c|c|}
\hline Name of drug & $\begin{array}{c}\text { Receive preferential treatment } \\
(\mathbf{\% )}\end{array}$ & $\begin{array}{c}\text { Doesn't receive preferential } \\
\text { treatment (\%) }\end{array}$ \\
\hline Nutrition & 10 & 90 \\
\hline ARTs & 30 & 60 \\
\hline TB & 10 & 90 \\
\hline Anti-malarial & 35 & 65 \\
\hline Condoms and contraceptives & 10 & 90 \\
\hline None & 5 & 95 \\
\hline Total & 100 & \\
\hline
\end{tabular}

Source: Fieldwork (2018)

Table II above shows the preferences on health commodities by personals involved in inventory management given a limited space for storage. Drugs that were most preferred were Anti-Malarial 
Rogers, K. T., \& Desderio, C. M. (2020) Towards Effective Inventory Management Of Health Commodities At Service Delivery Points: A Case Of Health Personnel In Shamva District, Zimbabwe. Archives of Business Research, 8(5). 248-262.

(35\%), followed by ARV's with 30\% preference rate, TB drugs and Condoms and Contraceptives shared the same preference of $10 \%$ of the respondents and least preferred was Nutrition drugs. However, there was a very small proportion of respondents which preferred drugs to have at equal preference since drugs are all equal important in the same way ( $5 \%$ of the respondents). The above reflects negative attitude and perception that is biased towards other drugs at the expense of others by personnel that are involved in the management of health commodities sorely at their discretion. This can be catastrophic as inventory management of other drugs that are deemed as not being important could be neglected and this could exacerbate problems of stock-outs and expiries.

On the point of delivery of commodities that have been ordered, the personnel that are responsible for inventory management of health commodities have to check the following: packing/delivery note, that all boxes are sealed, check that there is integrity of the product, count boxes and check the expiry of commodities (table III).

Table 3: Checklist at delivery points

\begin{tabular}{|c|c|c|c|c|}
\hline checklist at delivery & Yes & No & Yes (\%) & No (\%) \\
\hline packing/delivery note & 12 & 8 & 60 & 40 \\
\hline boxes are sealed & 15 & 5 & 75 & 25 \\
\hline Integrity & 19 & 1 & 95 & 5 \\
\hline count boxes & 20 & 20 & 100 & 0 \\
\hline expiry & 20 & 0 & 100 & 0 \\
\hline
\end{tabular}

The data gathered indicates that the majority of facility staff undertake the tasks required at delivery of commodities. Given that at delivery most respondents follow protocol, it should follow that stock-outs and expiries are minimized. However the rate of expiries (Fig III) and stock-outs experienced in Shamva district suggests existence of a missing link at the service delivery points.

A study on discrepancies between timely delivery of medicines and stock-outs and expiries experienced at the health centres in Dar es Salam's regional hospitals by Kagashe and Massawe (2012), concluded that all public hospitals sourced all drugs and non-drugs consumable from the Regional Medical Stores as a first step to replenish stock, however at facility level most centres did not get their inventories translating into adequate medicine and commodity supplies in the hospitals and the result was needless deaths of patients, prolonged ailments and poor healthcare delivery. A similar trend is observed in Shamva district as despite delivery of the ordered commodities in the right quantity and quality at time of delivery expiries and stock-outs are still experienced in the majority of the service delivery centres. It is apparent few of the health centres are conducting proper inventory management of health commodities before and after delivery of commodities and as such problems of erroneous ordering (ordering the wrong commodity in terms of type and quantities), over-ordering (leading to expiry of commodity in storage) and under-ordering (resulting in stock-outs) arise impinging on quality healthcare.

Fig V quantifies the drugs which expired between June 2018 and October 2018 at service delivery points in Shamva. 


\section{QUANTIFYING EXPIRIES AT SERVICE CENTRES}

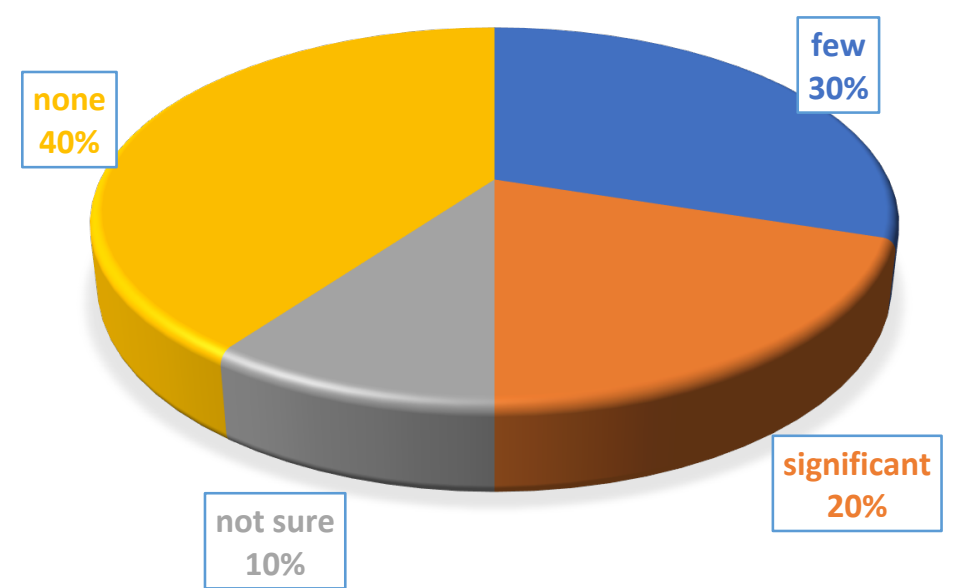

Fig 5: Quantifying expiries at service centres

Source: fieldwork (2018)

The personnel handling drug at the facilities responded to the questions on quantity of drugs that expired. At $30 \%$ of the facilities few drugs expired within the given timeframe, whilst at $20 \%$ of the facilities a significant amount of drugs expired, giving a cumulative total of $50 \%$ of facilities experiencing expiries between June and October 2018. 40\% of facilities experienced no expiries. On the extreme $10 \%$ of the facilities did not have data on whether any drugs had expired or not indicating unavailable or incomplete inventory management? Given that the majority of respondents indicated undertaking the checklists in table III expiries of this magnitude point towards weak KAPP of people tasked with storing, distributing, ordering and re-ordering the drugs.

To illustrate $100 \%$ of the respondents check expiry dates of drugs on delivery, however drugs expire in storage and this points towards over-ordering (stemming from poor data collection) and or poor distribution. Ideally expiries should be minimal or non-existent at service delivery points in Shamva if all personnel had had been trained of the following programmes Zimbabwe Assistant Pull System (ZAPS), Zimbabwe ARV Distribution System (ZADS), Voluntary Medical Male Circumcision (VMMC) and Medicine Management (MM) because the training stipulates drugs are to be distributed to the district and then to the province for redistribution, six months before the expiry date. This suggests a knowledge gap on the part of personnel responsible for inventory management of essential health commodities and leading to negative practices.

Various measures can be used to reduce expiries and stock-outs and Fig VI investigates which method personnel deemed to be most effective. 


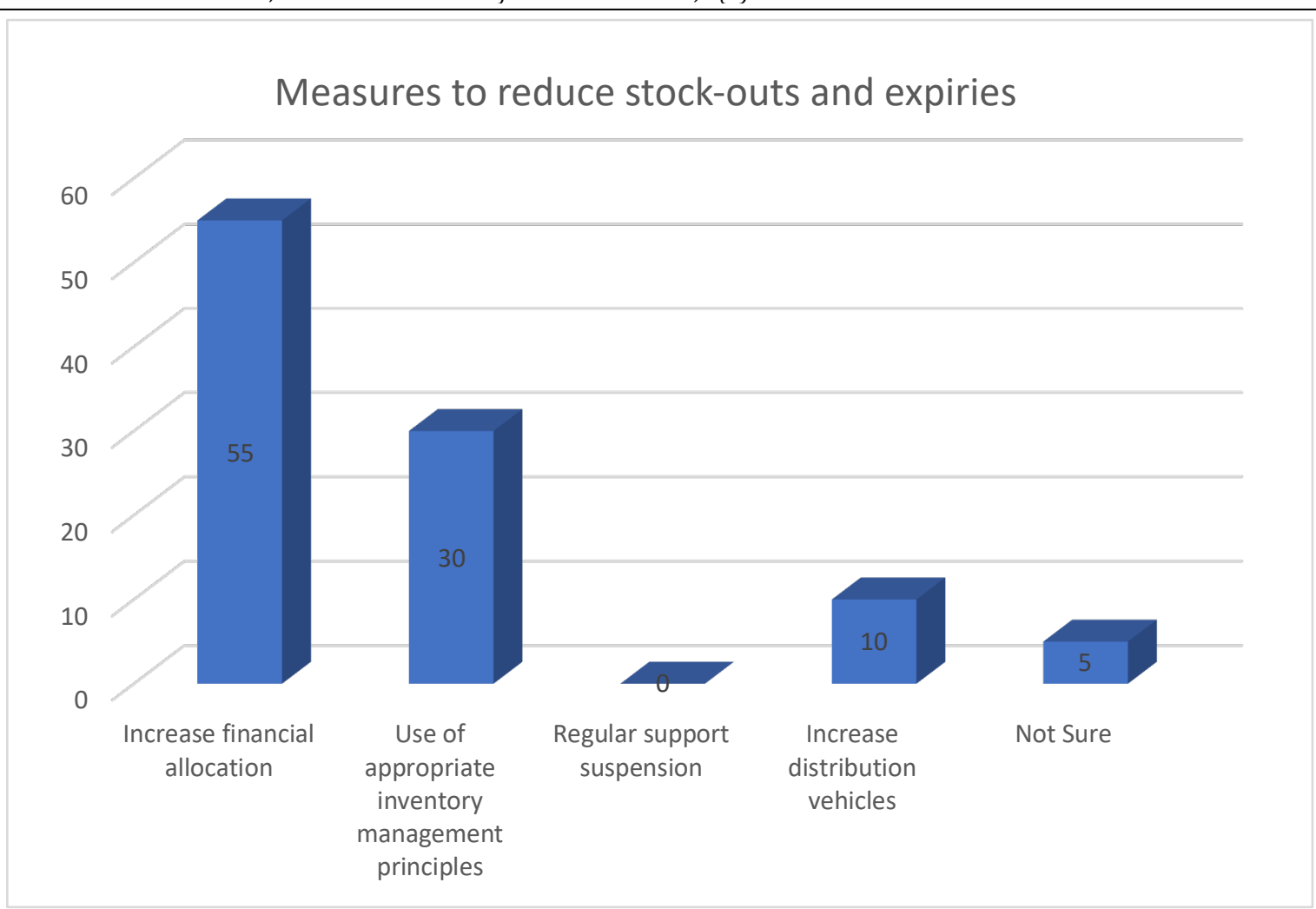

Source: Fieldwork (2018)

Fig 6: Measures to reduce stock-outs and expiries

Queried on what they perceive as the best methods to reduce stock-outs and expiries at their facilities the majority of respondents (55\%) indicated that increased financial allocation was more important. $30 \%$ are of the opinion that there is need for use of appropriate inventory management principles while $10 \%$ ascribe t the notion of increasing delivery vehicles and 5\% were not sure. The perception by personnel of what's important in reducing stock-outs and expiries is critical as it will influence how often and thoroughly inventory management is undertaken. This is apparent in the study area as due to a low number of respondents highlighting inventory management is important, practice on the ground talks to such attitudes and perception as inventory management is below stipulated standards. 


\section{Other factors contributing to the stock out and expiry of health commodities}

Beside personnel KAPP the study sought to explore if there are other factors contributing to commodity expiry and stock-outs. Figure VII and VIII explore these factors that could potentially lead to stock-outs and expiries.

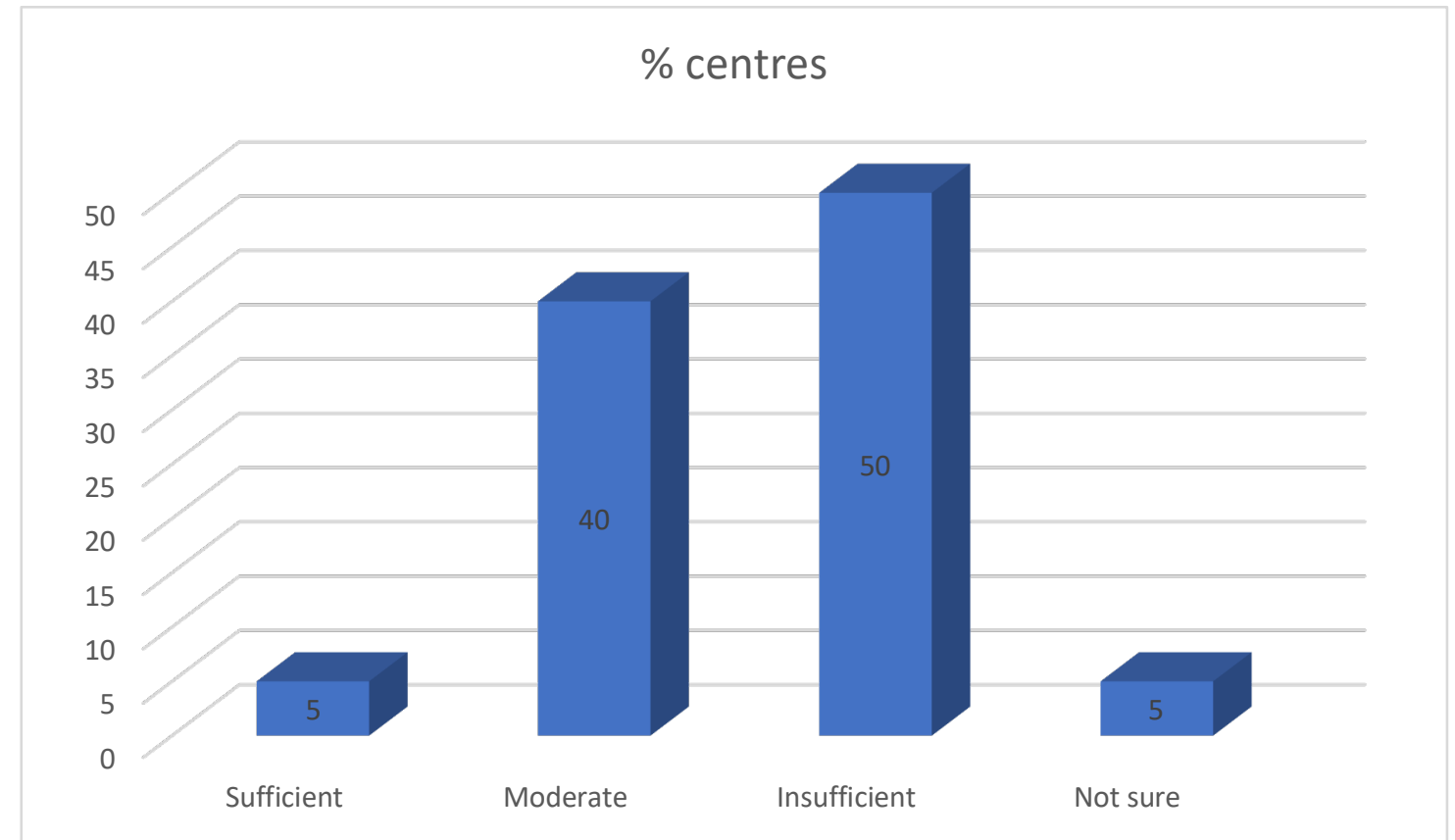

Fig 7: Allocation of funds for essential medicines by authorities

Source: Fieldwork (2018)

Fig VII shows the frequencies and percentage of the allocation of funds to health commodities from different authority's .e.g. government, NGO's and the private sector. Half of the respondent (50\%) suggested that the funds were inadequate for purchasing health commodities, followed by the respondents who said the funds distributed to the facility was moderate (40\%), this leads to stock out of health commodities. The allocation of funds to health facility may be a factor to consider on stock-outs of health commodities and this in addition to personnel KAPP should be improved on to reduce stock-outs and expiries.

Fig VIII shows the frequencies and percentage of the availability of health commodities on the market for the past two years. The perception of the respondent on the availability of health commodities were as follows sufficient (45\%), moderate (25\%) and insufficient (20\%) and those not sure $(10 \%)$. Although the majority of respondents indicated that medicines on the market were sufficient the $20 \%$ that indicated inadequacy should not be overlooked. This implies that in addition to problems of inventory management, at times medicines may be unavailable on the market. As such there is need for a holistic approach in studying stock-outs and expiries. 


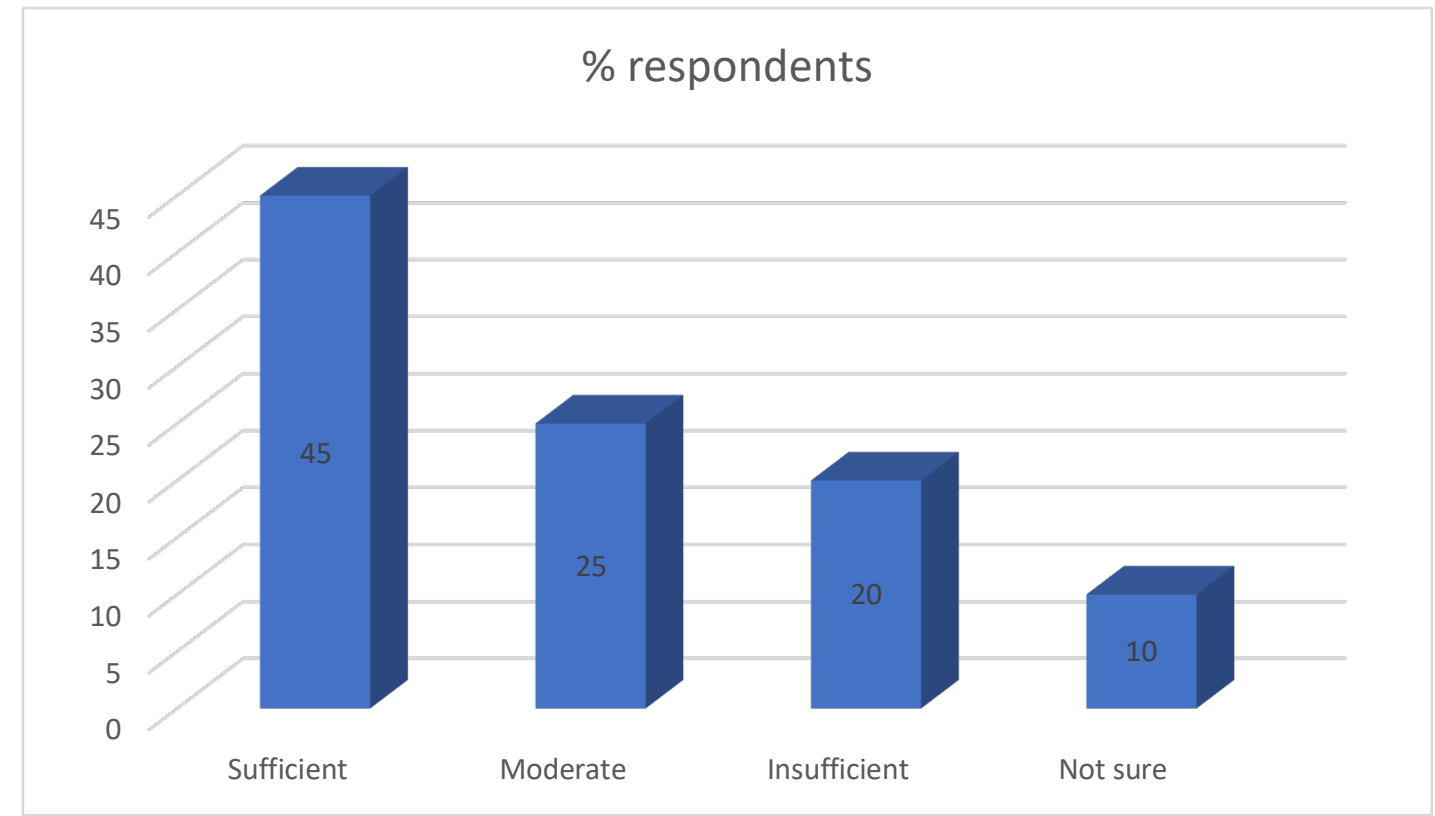

Fig 8: Availability of medicines on market for the past 2 years

Source: fieldwork (2018)

\section{Correlation analysis of the data}

The correlation was used to measure the intensity of the relationship between the timely supply of drugs by NatPharm and the knowledge of health personnel that is involved in inventory management of health commodities (table IV).

Table 4: Correlations

\begin{tabular}{|c|c|c|c|}
\hline \multicolumn{2}{|c|}{} & Timely supply & $\begin{array}{c}\text { Knowledge of } \\
\text { lead time }\end{array}$ \\
\hline \multirow{3}{*}{ Timely supply } & Pearson Correlation & 1 & .206 \\
\cline { 2 - 4 } & Sig. (2-tailed) & & .383 \\
\cline { 2 - 4 } & $\mathrm{N}$ & 20 & 20 \\
\hline \multirow{2}{*}{$\begin{array}{c}\text { Knowledge of } \\
\text { lead time }\end{array}$} & Pearson Correlation & .206 & 1 \\
\cline { 2 - 4 } & Sig. (2-tailed) & .383 & \\
\cline { 2 - 4 } & $\mathrm{N}$ & 20 & 20 \\
\hline
\end{tabular}

The value of the Pearson correlation coefficient was 0.296 , which suggests that there is a weak positive correlation between the timely supply of drugs by NatPharm and knowledge of lead time by health personals involved in inventory management of health commodities. Furthermore, the Pearson test was conducted to test if the correlation of 0.206 was it significant. The probability value was 0.383 which is far greater than five percent level of significance, which suggests that there is enough evidence to conclude that the correlation of 0.206 is insignificant for the relationship between timely supply by NatPharm and the knowledge of the health personnel about the lead time of drugs after ordering 
The relationship between the timely supply by NatPharm and knowledge of the respondent of the lead time of health commodities.

The knowledge of the lead time of drugs and the timely supply of drugs by NatPharm was investigated using Pearson Chi-Square, The Likelihood Ratio and Linear by Linear association. This measured the association of the knowledge of the lead time and timely supply for drugs by health personals that are involved in inventory management of health commodities (illustrated in table V).

Table 5: Chi-Square Tests

\begin{tabular}{|c|c|c|c|}
\hline & Value & Df & Asymp. Sig. (2-sided) \\
\hline Pearson Chi-Square & $7.758^{\mathrm{a}}$ & 8 & .457 \\
\hline Likelihood Ratio & 6.201 & 8 & .625 \\
\hline Linear-by-Linear Association & .809 & 1 & .368 \\
\hline N of Valid Cases & 20 & & \\
\hline
\end{tabular}

Table $\mathrm{V}$ is a chi-square test to investigate the association between the knowledge of lead time of drugs to be supplied and timely supply of drugs. The probability values of methods suggested above are less the five percent level of significance, there is enough evidence to suggest that there is no association between the knowledge of lead time and timely supply of drugs by NatPharm. This indicates a gap of knowledge of the personnel involved in health commodities about the lead time of drugs to be supplied by NatPharm.

\section{DISCUSSION OF RESULTS}

The study findings indicate that the people tasked with inventory management vary in terms of professional designation, due to there no being personnel employed expressly to undertake inventory management at service delivery points, thus personnel employed in at the centres in capacities of nurses, nurses, sister in charges and general hands among others have the additional responsibility of inventory management. According to Rushton et al. (2010), the inventory management function has evolved from being perceived as an administrative support where there was little or no support and comprehension of the importance of good inventory management by personnel tasked with undertaking it and the contribution that it could make to corporate success as organizations are beginning to accept that inventory management is a vital ingredient to overall business success and as such personnel involved in inventory management require exhaustive training. The notion of personnel requiring exhaustive training transcends the business sector and is equally applicable in healthcare inventory management. There are various aspects which health workers involved in inventory management need to be trained in and these include ZAPS, ZADS, MM, and VMMC AND VMC. There is however poor uptake of most of these training programmes and this ultimately results in poor KAPP by health personnel at these service delivery points and this has impacted negatively on personnel KAPP as lack of knowledge equates to negative poor attitudes and perception towards stock control and ultimately negatively affecting practice.

To exacerbate the problem, in addition to poor uptake of initial training in inventory management refresher courses are even less common (table I). This is against a backdrop of quality healthcare delivery being premised on availability of health commodities in the right quantity and right quality, at the right time. Inventory mismanagement has negative connotations for both financial (lost revenue through stock-outs and expiries) and operational (poor service delivery due to 
Rogers, K. T., \& Desderio, C. M. (2020) Towards Effective Inventory Management Of Health Commodities At Service Delivery Points: A Case Of Health Personnel In Shamva District, Zimbabwe. Archives of Business Research, 8(5). 248-262.

unavailability or shortage of commodities) sectors of health service delivery (Rushton et al.; 2010). Refresher training is thus of paramount importance as it can encourage good inventory management practices by facility staff. Consequent to poor uptake of refresher courses by personnel in Shamva district. Knowledge of personnel is compromised and this is leading to poor practice which is exemplified by frequency of inventory management undertaking being lower than the standard and the resultant stock-outs and expiries associated with poor inventory management.

Health personnel responsible for inventory management of health commodities were biased towards Anti Malaria commodities than any other health commodity. The contributing factor is that most of the facilities' staff recognised that malaria is a deadly disease if not treated early. The health commodities that were preferred after Anti-Malaria were Tuberculosis and Antiviral Treatment commodities which are diseases that are on the rise in Zimbabwe. However, there is less preference of nutrition commodities, Condom, and contraceptive commodities. Such preferences (borne of the perception of personnel undertaking inventory management) are problematic as they influence the attitude of the personnel towards proper stock-taking for commodities and medicines with medicines that are preferred receiving more attention, thus more thorough attention as opposed to medicines deemed less important in which case inventory management for such drug could be sub-par. This suggests that health personnel have to understand that the health commodities are to be prioritized equally as all are important in the treatment and prevention of diseases.

Kumar (2015) postulates that in instances were costs and storage space do not allow a balance needs to be struck to achieve optimal health service delivery and the scholar further encourages the use of VED (Vital, Essential, Desirable) analysis to categorize commodities in the three groups and compute quantities of each commodity ordered informed by the category it falls under. Such an approach has been employed successfully in Indian army medical facilities and has potential to improve stock management in Shamva district an indeed Zimbabwe as a whole. The important thing to note is that such an analysis should be done at higher levels rather than each facility independently deciding on which drugs to priorities at the prerogative of facility staff. In Shamva district as the results highlight no scientific analysis has been done relating to prioritization of drugs if need arises, and as such the prerogative of health personnel involved in inventory management at the particular time takes precedence. Resultantly priority drugs are erratic across the district (table II) resultant of there being no yardstick of what drugs are to be prioritized should there be cost and space impediments and to what extent as well as the measures to ensure other drugs are not completely side-lined.

At the delivery point, the health personnel indicated they checked the packing/delivery note, checked that all boxes are sealed, checked that integrity of the drugs, counted boxes and checked the expiry of received commodities. Despite protocol being followed at delivery, when queried about level of stock-outs and expiries the data gathered reveal that at half of the centres under study stock-outs were experienced between June and October 2018. In 10\% of the centres there was no data pertaining to and personnel could not recall if they had experienced stock-outs and expiries between June and October 2018. Kumar (2015) quantifies the variations in service delivery at primary health centres being explained by the order quantity, reorder level, personnel management of inventory, and willingness of personnel involved in inventory management to 
employ emerging theories like just in time and activity based costing. The scholar thus infers that if ordering and reordering at facility level is erroneous, inadequate or excess commodity will be delivered. Thus, considering the checks done at delivery to ensure what was ordered has been delivered, the fact that only forty percent (40\%) of centres did not experience stock-outs and expiries within the aforementioned months points to ineffectiveness in the inventory management at the centres (ordering, storage, re-ordering, record keeping and distribution).

\section{RECOMMENDATIONS}

1. There should be partnerships between all stakeholders in the health sector (government, NGOs, academic institutions training health personnel (etc.) to ensure that adequate and relevant training pertaining to inventory management is continually proffered so that procedure and importance of inventory management and are ingrained into personnel. Currently, training is highly inconsistent with training rendered being sore to the discretion of training institutions and the personnel themselves (in terms of seeking further training). As such, there is a need for dialogue by all stakeholders to create a single training manual on procedure and importance of inventory management manual which should be used in training of all personnel at all academic institutions and service centres.

2. There is a need to come up with benchmarks on good practice when it comes to inventory management and supply chain as a whole. The data collected at various service centres indicated that inventory management is done inconsistently and aspects of ordering, reordering, and stock-outs, as well as expiries, fluctuated from one service centre to the next. There is thus need for creating of benchmarks for what constitutes good practice (e.g. less than $1 \%$ expires and stock-outs), accompanied with penalties for poor performance.

3. There is need to raise awareness that Health Commodities Inventory Management is an important discipline on its own which contributes immensely to the overall Health delivery system of any setting be it at the national level or down to service delivery point level. It is a mainstream activity, not a supporting activity (No commodity on the programme) many a time, programmes are set up and the supply chain aspect is totally forgotten or is considered to be of little or no significance. Awareness campaigns to be spearhead from the top.

\section{References}

1. Agrawaj et al (2016) Bibliometrics: tracking research impact by selecting the appropriate metrics Volume: 18 | Issue : 2 | Page :296-30

2. Chen et al. 2013) Development of online knowledge community evaluation model using the balanced scorecard approach. Shu-Chen Kao, ChienHsing Wu, Chieh-Lin Huang. Journal of Enterprise Information Management

3. Chingarande D (2018), 'HIV/AIDS Patients at Risk as Crucial Drug Expires', Newsday, Harare, 30 April 2018.

4. Development of a questionnaire to assess worker knowledge, attitudes and perceptions underlying dermal exposure. Scandinavian Journal of Work, Environment \& Health 32(3):209-1

5. Hinterplattner M (2016), 'Supply Chain Management in Hospitals: Impetus from Organisational and Behavioural Theories'. International Journal of Pharmacy

6. Kadirire H (2018), 'Zimbabwe runs out of TB drug', The Daily News, Harare, 26 August 2018

7. Kagashe G and Massawe T (2012), 'Medicine stock-outs and Inventory management problems in public Hospitals in Tanzania: A Case Study of Dar es Salaam Region Hospitals', International Journal of Pharmacy pp 252-259

8. Mahoro A. (2013) Examining the inventory management of antiretroviral drugs at community health centres in the cape metropole, Western Cape. Business 
Rogers, K. T., \& Desderio, C. M. (2020) Towards Effective Inventory Management Of Health Commodities At Service Delivery Points: A Case Of Health Personnel In Shamva District, Zimbabwe. Archives of Business Research, 8(5). 248-262.

9. MHS (2012) Mental Health in Sport (MHS): Improving the Early Intervention Knowledge and Confidence of Elite Sport Staff. ORIGINAL RESEARCH10.3389/fpsyg.2016.00911

10. Robson C and MacCartan C (2011), 'Real World Research'. New York: John Wiley and Sons

11. Rosen J.E., Ben J, and Wolf K. (2015), 'Evaluation of the Zimbabwe Assisted Pull System (ZAPS): Baseline Report.' Arlington, Va.: USAID | DELIVER PROJECT, Task Order 4.

12. Rushton, A., Croucher, P. and Baker, P. (2010), The Handbook of Logistics and Distribution Management Paperback - 3 Jun. 2010

13. Saunders M, Lewis P and Thornhill A (2009), 'Research Methods for Business Students'. New York: Pearson

14. Sekaran U (2001), Research Methods for Business: A Skills Building Approach'. New York: John Wiley and Sons Inc.

15. Silverman D (2009), 'doing qualitative research: a Practical handbook'. Los Angeles: SAGE Publications

16. The Global Fund. (2017) 'Audit Report the Global Fund's In-country Supply Chain Processes' [o]Available at https://www.theglobalfund.org/media/6363/oig_gf-oig-17-008_report_en.pdf?u=636637835730000000 (accessed 9 July 2018)

17. Transparency International. (2011), 'Kenya Health Integrity Study', Nairobi: Transparency International.

18. USAID | DELIVER PROJECT, Task Order 1. 2011. 'The Logistics Handbook: A Practical Guide for the Supply Chain Management of Health Commodities'. Arlington, Va.: USAID | DELIVER PROJECT, Task Order 1.

19. Wales J, Tobias J, Malangalila M, Swai G and Wild L (), 'Stock-outs of Essential Medicines in Tanzania: A Political Economy approach to Analysing Problems and Identifying Solutions' London: DFID

20. WHO (2008) Commission on Social Determinants of Health - final report 